\title{
Reference To Study Results
}

National Cancer Institute

\section{Source}

National Cancer Institute. Reference To Study Results. NCI Thesaurus. Code C93451.

A citation in an external publication that refers to results of this study. 